\title{
Extending the Frontiers of Library Services Through the Internet
}

\section{By}

\section{ACHONNA, A.U. and YAYA, J.A.}

\begin{abstract}
\section{Introduction}

Library and Information services have undergone various stages of transformation from inception. This dates back to the oral tradition era when human brain served as the repository of ideas, knowledge and information that were transmitted from one person to another through words of mouth. The obvious limitations of the library at this stage was the inability of the human brain to store and retain all the knowledge and information available and the subsequent demise of the human custodian which leads to considerable loss of valuable knowledge and information.
\end{abstract}

This paper examines the tremendous developments that have taken place in the Library and Information services from inception to the present day with a focus on the role of the Internet in these developmental trends. The prelude and the history of Internet were x-rayed with an insight into the meaning of the Internet. The role of the Internet in extending the frontiers of Library and Information services were explored with a review of the situation of Internet connectivity in Nigeria, the problems and recommendations.

Other factors that hastened the development of library and information services was the emergence of writing in places like Egypt, Babylon, Sumerian, Persia, Assyria and Phoenicia. At this time, knowledge and information were recorded on clay tablets, papyrus sheets, stones and parchment/vellum, papers, the back of trees preserved in the palaces of kings and queens. The library and its services at this stage were the exclusive preserve of the privileged class in the society.

The introduction of printing in the $16^{\text {th }}$ century by Jonan Gutenberg in 1450 helped in no small way to quicken the pace of library development as books were massively produced and made available at affordable prices.

Advances in science and technology gave rise to the information explosion with its attendant challenges of how to cope with the storage, retrieval and dissemination of information to numerous library users. The emergence of computers with its high storage and retrieval capabilities to meet these challenges facilitate the dissemination of information resources to library users. Also, the upsurge of virtual libraries and the Internet has helped to widen the scope of library and information services beyond the traditional norms.

A careful observation of the trend in the development of library and information services shows clearly that there has been a continuous and widening scope with the passage of time with regard to the overall performance in the services of the library and information centers.

\section{The Internet}

According to Rogers (1986), the Internet as an international interconnected network of computers, has made the world to graduate from the "global village to global pinhead. It is a global network of networks enabling computers of all kinds to directly and transparently communicate and share global resource of information, knowledge and means of collaboration, and cooperation among countless diverse communities. It consists of millions of computers linked together around the world in such a way that information can be sent from any computer to any other 24 hours a day. The computers can be seen in homes, schools, universities, government department or business, infrastructure that provides the greatest opportunities for all types of users especially library users to have wide access, and retrieve needed information from the pool of information resources on the net. The notion of Internet was based on the philosophy that every piece of information and data held electronically anywhere is potentially accessible to any user with correct computer and communication technologies. Internet information resources cover all areas of disciplines and knowledge such as librarianship, engineering, medicine, agriculture, economics, geography, geology, sciences, trade, commerce and interest to library users.

\section{Library and Information Services Provision through Internet}

The Internet has the potential to extend the services of library and information centers beyond its present scope. Hitherto, the services of library and information center have been confined by time and space due to the nature of its particular stock - book and other information materials. With the introduction of Internet into library and information center services, the world of library and information has to evolve into a global village because of capacity of the Internet technology to small and large. Besides, it is an information all other areas of knowledge, which could be of 
bring together a world of information from various global circles divides all meeting at the level of the information superhighway.

The Internet is an important product of information and communication technology. It is a collection of vast information sources of inter-linked computer networks. It is usually referred to as a network of networks. Millions of computers worldwide are interconnected and the information sources in each computer are made available to all users who have access to the Internet.

The Internet is accessible to all kinds of people academic, the military, businesspersons, students, schoolchildren, etc. Through the Internet, one can access bibliographic and full-text databases, library catalogues on OPAC, electronic mail, newspapers, magazines, constitutions of various countries, electronic commerce, etc. One of the most important facilities in the Internet is the World Wide Web which consists of a series of various computers that are linked to the Internet through a device called hypertext transfer protocol (HTTP). People create information on the web. Websites can be created on the Internet and they can be accessed through a browser. Each website has its universal resource locator (URL) - website address.

However, librarians can extend the frontiers of library services by deriving the following benefits from Internet facilities:

i. Rapid and convenient information exchange.

ii. Ease of access to experienced and expert persons in many field of knowledge.

iii. Quick access to regular updates on topics of interest.

iv. Fostering teamwork across wide geographic distance.

v. Transfer of data between machines.

vi. Wide access to archive information that could be useful to various library users.

vii. Provision of great opportunity for fun and entertainment thereby lessening fatigue, boredom and work stress.

viii. Assists access to information managers (librarians) in providing effective reference services to their users.

ix. Knowledge and other library materials can be easily organised as Internet websites provide classification database.

x. Librarians can acquire needed information resources for their libraries or information centers without going to the bookshops or book sale agents.

xi. Resources in the Internet permits librarians to provide value added information services to their clienteles, and

xii. It reduces the cost of providing information service to users.

\section{Internet Application}

There are many internet applications useful for the library and information services.. They include email, mailing lists, Usenet, loading of relevant information/articles from any source in the world or any institutions across the globe, etc. For example:

e-Mail: The electronics mail (e-mail) is one of the important applications of the Internet. Through it, one can forward and send messages to any user of e-mail. As long as a user has an e-mail address, he/she can enjoy this facility. The advantage of an e-mail over the postal system is that the message is accessed instantaneously once the e-mail address is correct. One can also send any computer file such as texts, images, etc, through file attachment. Thus, through this device, one can send full-texts of documents, scanned images, etc to a library user. Another advantage of the e-mail is that a can send one message simultaneously to multiple users. In addition, a copy of an e-mail sent to a library user can also be copied to other users through the device, carbon copy (cc). A sender can also send a message to a user and copy other users without the receiver knowing that the same message has been copied to other users through the device, blind carbon copy (bcc) in order to send an e-mail, the sender uses the 'compose option' of the e-mail service. If a message is received, the receiver may reply the sender without necessarily going through the 'compose option'.

The computer, whether received or sent, stores mail messages, unless they are deleted. These messages are well managed, and they can sort by date, sender, subject, etc. If it is sorted by date, all the messages will be sorted according to the date the message was received. If it is by sender, the messages will be sorted according to the sender's names in an alphabetical order. If subject sorts is adopted, the messages will be sorted according to the subject of the mail in an alphabetical order. (Bloomberg and Evans, 1985).

Mailing List: This is a list of an association of users with common interests such as registered library users. A user will join a mailing list by providing his/her user address to the administrator of the list. Any message sent to that list will be automatically available to all users who subscribe to the list. Since these users have common interests, sending a message to the list usually encourages discussion. For example, there is an African libraries mailing list where most users interested in Africa librarianship are members. 
Mailing lists are also called Listery. These mailing lists can be moderated or unmoderated. When messages are sent to the list and they become available to other users instantly, such messages are said to be unmoderated. Moderated messages are first screened before they are relayed to other users. Hence libraries could decide on which option to maintain

Usenet News Groups: This is a community of users who share ideas on every subject imaginable. Aina (2004) opined that there are many newsgroup on the Internet to which a user can belong. A Usenet group acts like public notice board on the internet. Any user that has access to the Internet can read the message on the notice and react publicly by posting the message on the board or privately by sending the messages through the email of the contributor. The Usenet news groups cover all kinds of subjects such as sports, engineering diabetics, librarianship etc. Thus libraries could have their usernet for their users.

On-Line Searching: This is one of the major products of the convergence of computers and telecommunications technology. It has greatly improved the provision of library and information services to users. Through information communication technology, (ICT) a user is able to access the information, both bibliographic and fulltext, in several million documents over a long distance. A user can access the information required once there is a match between a search term and the document descriptors used for describing the documents needed. On-line searching is a direct communication between a user and the computer system in an interaction mode. It is usually fast, accurate and comprehensive and involves making requests of what is needed through a keyboard, which appears on a screen. Then the computers system will communicate with another computer system containing databases required in a remote place. The databases are usually a collection of related files, which may be bibliographic, full text or numeric. It is therefore important that libraries do not only get connected to the Internet but also subscribe to online databases.

\section{Some Possible Websites and their Uses}

In order to find global resources list and collections, institutional information servers, search other library resources, directories of jobs, conferences, electronics publications, contents of journals and books, abstracts and index publications news books in databases, OPACS, software, standards and librarianship resources by subject refer to: http://www.lub.lu.seineliab/documents/lisres.html
In order to find information on recruiting new professionals to the field of library and information science refer to http://alexia.lis.uiuc.edu/clips/2003 02.html

In order to locate UNESCO libraries portal: librarianship/jobs refers to site: http://www.unesco.org/web world/portal bib/librarianship/jobs/

In order to use yahoo to provide free e-mail for users, campaigns by advertisers and also features a search engines and features a search engines refer to www.yahoo.com

In order to use goggle to site many scientific presentations, discussion forums for registered users and features a search engine refer to www.goggle.com.

\section{Conclusion}

There is no doubt that the internet communication technology has great potentials for the developed nations of the world, but more so to the developing nations like Nigeria. The scope and horizon of library and information centers/services stand to benefit beyond the present status in this $21^{\text {st }}$ century. This is certainly a welcome development in the information age, which is characterized by knowledge explosion and access to the information superhighway. Hence, as the world continuous to shrink into a global village, it becomes imperative for every nation, organization and individual to wake to the challenges of keeping abreast with the global communication technology of the Internet.

\section{References}

Achilike, J. C. (2002). Print Media Technology in Nigeria: An Appraisal of a seminar in Mass Communication Technology. ESUT Business School, Lagos.

Adio, O. (1999). "Rolling over to Internet". The Guardian, February2, pp 15.

Alokun, N.A.T. (2003). The use of Library: A textbook for students in tertiary Institutions, Lagos: Nudex International Company.

Aina, L.O. (2004). Library and information science text for Africa. Gaborone, Botswana:

University of Botswana.

Ausbeth - Ajagu, Anuli (2001). "The internet and its relevance in global communication technology". Seminar in Mass Communication Technology, ESUT Business School, Enugu.

Bloomberg, M. and Evans, C.E. (1985). Introduction to technical services for library technicians, $5^{\text {th }}$ edition. Littleton: Libraries Unlimited. 
Collin, Simon (1997). Doing Business on the internet. London: Kogan Page.

Ngoa, Naribo S. (2001). "Computer revolution: Contemporary mass media and interactive

Communication". Seminar in mass technology. ESUT Business school, Enugu.

Okonkwo, R.K. and Ade Afolabi (1998). "The challenges of information technology and globalization for the Nigerian Financial System". NDIC Quarterly, September /December, vol 8 (5314).

Olanlokun, S. O. and Salisu, T.M. (1993).

Understanding the library: A handbook on library use. Lagos: University of Lagos Press.
Oloruntoba, B.S. (1997). "Internet, what is it? Computer Plus Magazine, October, vol. 1.

Issue 4. pp $9-12$

Ononogbo, R.V. (1985). Enriching information resource through keeping contact with information. National Library and Information Science Review, vol.391 (2), pp 55-62.

Ovia, Jim (1998). "Internet and banking". The Nigerian Treasurer, Jan - March, pp $12-15$.

Roggers, E.(1986). Communication technology: The New Media Society. New York: The Free Press. 